\title{
Brizola e o trabalhismo
}

Angela de Castro Gomes*

\begin{abstract}
Resumo. A partir de reflexões suscitadas pelos funerais de Leonel Brizola, o artigo analisa o trabalhismo enquanto uma ideologia e uma tradição política, que compõe uma cultura política compartilhada no País a partir de 1945. Mostra como o trabalhismo, que tem sua gênese no pós-30, foi relido e apropriado por trabalhadores e lideranças políticas e sindicais ao longo do período 1945-1964 e discute as transformações decorrentes do suicídio de Vargas, bem como aquelas pelas quais o trabalhismo passou após 1979, quando ele se encarnou no brizolismo. Palavras-chave: Brizolismo. Trabalhismo. Cultura política.
\end{abstract}

O tema deste pequeno texto é Brizola e o trabalhismo. O artigo tem como objetivo realizar alguns poucos comentários, e, como manda o figurino, começarei por Leonel Brizola. Foi, sem dúvida, o falecimento de Brizola, ocorrido em 21 de junho de 2004, uma

*Angela de Castro Gomes é pesquisadora do CPDOC/FGV e Professora Titular de História do Brasil da UFF. Este texto foi escrito para ser apresentado na MesaRedonda Brizola e o trabalhismo, que a autora coordenou no Encontro Regional da ANPUH-RJ, em 19 de outubro de 2004; daí as características de tamanho e forma do artigo.

Anos 90, Porto Alegre, v. 11, n. 19/20, p.11-20, jan./dez. 2004 
segunda-feira, que deu o mote para essas reflexões. Mas não porque Brizola precisasse morrer para ser objeto de estudo de cientistas sociais e da atenção de uma ampla parcela da população brasileira. Afinal, ele era e continua sendo reconhecido como uma das grandes figuras da política brasileira contemporânea, isto é, da política que tem como marco simbólico a Revolução de 1930. Essa foi uma revolução de elites ou uma revolução pelo alto, como foi e ainda é considerada, e, justamente por isso, produziu uma renovação, inclusive geracional, nos integrantes da classe dirigente do País, na qual passou a se incluir o gaúcho Leonel Brizola.

Com longa trajetória política, que atravessou várias das repúblicas do Brasil, Brizola foi um personagem que deixou a marca de sua presença, para o bem ou para o mal, como quisermos, em mais de um momento estratégico da história recente do País. Ele agiu e falou muito, mas morreu sem conceder uma entrevista de história de vida, apesar de tê-la prometido muitas vezes, nos últimos cinco anos. Estou convencida de que Brizola morreu "antes da hora", ao menos segundo sua própria perspectiva. Ele mesmo garantiu, em várias oportunidades, que viveria ainda muitos anos e que não faltariam oportunidades para a tal entrevista "de historiador", como gostava de dizer. ${ }^{1}$

De qualquer modo, quando Brizola morreu, o que se viu, em seu funeral, foi uma grande e espontânea manifestação popular de apreço tanto por um político, como por um certo passado político. No Rio de Janeiro, em Porto Alegre e, não casualmente, em São Borja - onde Brizola foi enterrado ao lado de Getúlio e Jango -, o povo, o povo mesmo, participou do último ritual cívico em que o corpo do político esteve presente. E esse é o primeiro ponto que quero destacar no texto.

Funerais, como os antropólogos advertem-nos com fartura, são rituais estratégicos, plenos de significados religiosos e também, em episódios específicos, políticos. No caso da morte de figuras políticas, os funerais costumam se tornar um momento de consagração de suas vidas. Trata-se da ocasião em que, morto o corpo, a alma torna-se imortal, como imortais tornam-se alguns de seus

Anos 90, Porto Alegre, v. 11, n. 19/20, p.11-20, jan./dez. 2004 
"feitos", selecionados e ressignificados pela memória, poderosa força que permite "que se saia da vida para entrar na história".

Nessa chave, os funerais de Brizola inserem-se em uma tradição de rituais desse tipo que, no Brasil, data pelo menos da Primeira República (cf. Gonçalves, 2000). Diversas personalidades - do mundo político, da ciência e das artes, por exemplo - foram consagradas por rituais cívicos de enterramento nesse período. Dessa forma, era clara a existência de uma estratégia de se produzir uma galeria de heróis nacionais ou, pelo menos, de figuras exemplares que mereceriam ser lembradas e que se situariam ao lado de outras, que vinham sendo consagradas pela narrativa histórica. Aliás, vale também lembrar, uma narrativa histórica que se reestruturava em função do novo regime republicano e que, exatamente por isso, era campo de disputas simbólicas acirradas, evidenciando reavaliações de personagens e eventos.

Rituais, como se sabe, são encenações sofisticadas, plenas de significados simbólicos, em que uma linguagem é mobilizada e hierarquias de valores são expostas e confirmadas. Porém, tudo isso não elimina a possibilidade de os rituais comportarem espontaneidade e participação, até certo ponto imprevistas. Os rituais políticos, como tudo na política, guardam um certo grau de incerteza e imprevisibilidade. Como fenômenos de delicada construção e aprendizado político-cultural, eles também conservam as inúmeras e insuspeitas possibilidades de leituras e apropriações de seus públicos, que são sempre muito diversos.

Os funerais de Brizola, nesse sentido, têm um passado longo. $\mathrm{Na}$ Primeira República, pode-se lembrar o de Machado de Assis (1908), de Euclides da Cunha (1909), de Joaquim Nabuco (1910), do Barão do Rio Branco (1912), de Pinheiro Machado (1915), de Osvaldo Cruz (1917), de Rui Barbosa (1923) e de João Pessoa (1930), entre outros. ${ }^{2}$ Esse foi um período estratégico à proposição e encenação desse tipo de cerimônia e, particularmente, para sua significação e uso na construção de uma cultura política republicana no País. Para que a lista não se alongue, é bom lembrar logo dos funerais de Getúlio Vargas (1954), Juscelino Kubistchek (1976) e

Anos 90, Porto Alegre, v. 11, n. 19/20, p.11-20, jan./dez. 2004 
de Tancredo Neves (1985), para não falar no funeral de um novo tipo de herói nacional, cuja figura emblemática é Airton Senna.

Conforme os antropólogos ensinam e os historiadores aprendem com rapidez, funerais, enquanto rituais cívicos, são momentos em que os mortos ilustres são identificados como figuras entre sagradas e insignes. De toda forma, são situados como figuras cuja ausência é uma inequívoca perda para a nação e para o povo brasileiro pelo que eles significaram em vida. Assim, nesse momento liminar, quando a morte física conduz à imortalidade, realiza-se uma operação extremamente sofisticada de "trabalho da memória", que deve ser reforçada e consolidada com o passar do tempo. Mas, como todo "trabalho da memória", esse também não é arbitrário, embora seja evidentemente seletivo, pois ocorre uma seleção que tem como campo de explicação o presente e não, necessariamente, a trajetória do morto, em suas complexidades e ambigüidades. Em palavras simples, trata-se exatamente de dizer/escolher sob a ótica do presente, o que torna o morto uma figura exemplar, símbolo de algo que pode e deve ser amplamente admirado e lembrado daquela data em diante. Por isso, a proposta de se trabalhar com a idéia de "alegoria às avessas" é muito atraente.

Como mencionei, os funerais são cerimônias que podem se transformar em rituais cívicos, nos quais o que se cultua, por excelência, é a Pátria, ali representada pela pessoa do morto ilustre. Nessa dinâmica simbólica, o que geralmente ocorre é que cada uma dessas figuras encarna um certo aspecto da Pátria, o que permite e mesmo exige a sua celebração como imortal. Logo, esses indivíduos materializam, para a sociedade como um todo, um certo atributo especial que possuíam em vida e que passa a estar ligado a eles de maneira definitiva após a morte. É a essa operação cultural que estou chamando de "alegoria às avessas", ou seja, ao invés de uma idéia ou sentimento serem dotados de um corpo para representá-los, um corpo real e morto passa a simbolizar uma idéia e a ser com ela identificado: Osvaldo Cruz, a ciência; Rui Barbosa, o Direito etc.

Observando os funerais de Brizola e também deles participando, bem como lendo com cuidado uma parte do material

Anos 90, Porto Alegre, v. 11, n. 19/20, p.11-20, jan./dez. 2004 
da imprensa produzido sobre ele, neste momento, arrisco uma hipótese: ${ }^{3}$ Leonel Brizola, no momento de sua morte, foi alçado à categoria de um nome ligado às lutas pela democracia no Brasil. A meu juízo, portanto, a imagem mais recorrente e forte de sua presença política, a imagem que se escolheu fixar para ser especialmente lembrada, foi a do defensor da legalidade institucional, através do episódio de 1961, de luta pela posse do presidente João Goulart. Foi então que Brizola emergiu como uma figura de líder inconteste: corajoso e guardião dos valores democráticos. No caso, não importa que ele não tenha tido tais posições ao longo de toda a sua vida política, e ele, de fato, não as teve, como atestam os mesmos jornais, que reconhecem esse fato claramente, assumindo tons críticos e não escamoteando os pendores autoritários da personalidade e presença políticas de Brizola. O funeral, como uma data comemorativa que faz lembrar -, não encontra sua justificativa no passado, mas no presente; não somente naquele que é lembrado, mas também naqueles que estão lembrando. Por conseguinte, os funerais e todo e qualquer ritual cívico operam com os valores que se querem guardar em determinado momento do tempo e do espaço. Se, em 2004, Brizola permitiu-nos reforçar o culto aos valores democráticos, tanto melhor para ele e para nós, arrisco também a dizer. Agora, então, é a vez do trabalhismo, ou melhor, dos trabalhismos.

Minha idéia, aqui, é deixar claro que estou entendendo o trabalhismo tanto como uma ideologia política, quanto como uma tradição política, pertencente ao universo de fenômenos que integram o que se pode considerar uma cultura política bastante compartilhada no País a partir da República que se instaurou em 1945, após a queda do Estado Novo. A categoria trabalhismo, portanto, desde então, passou a ser utilizada e identificada quer em textos da academia, quer em textos da grande imprensa, quer no vocabulário político comum, com razoável abundância e facilidade. Ideologias e tradições fazem parte das culturas políticas de uma sociedade e devem ser pensadas como construções intelectuais possuidoras de uma dinâmica e de uma história próprias. 
Quero dizer, com isso, que o trabalhismo, como ideologia, foi "inventado" em momento e circunstância bem precisos, não tendo origens remotas, nem imemorias, muito pelo contrário. Envolvendo um conjunto de idéias, valores, vocabulário e também práticas festivas (como um certo tipo de comemoração do Dia do Trabalho), o trabalhismo, como ideologia, foi um produto do Estado Novo em seu segundo movimento. Isso significa que tal ideologia foi articulada e difundida através de uma série de modernos e sofisticados procedimentos e atos comunicativos, a partir do ano de 1942, possuindo como base operacional o Ministério do Trabalho, Indústria e Comércio, então comandado por Alexandre Marcondes Filho.

Desde então, passou a ser propagada e fortemente vinculada à figura pessoal do então Chefe de Estado, Getúlio Vargas, além de traduzir a idéia capital de responder aos interesses dos trabalhadores, por meio do acesso a uma legislação trabalhista, previdenciária e sindical. Portanto, a ideologia trabalhista nasceu vinculada ao getulismo, ao nacionalismo e ao intervencionismo de um Estado protetivo que Vargas então encarnava. Do mesmo modo, a ideologia trabalhista nasceu vinculada a um modelo de organização sindical de extração corporativista, o que, naquele contexto político, significava uma forma de representação de interesses profissionais e não de idéias políticas, religiosas etc. A ideologia trabalhista e o sindicalismo corporativista compunham o que se designava "democracia autoritária" brasileira, vale dizer, uma forma de democracia que consagrava os direitos sociais e criticava e desprezava a democracia política e, por conseguinte, o voto, os partidos, as eleições, o parlamento etc.

Como ideologia política (e não uso a categoria como significando deformação de idéias), o trabalhismo caracterizou-se por um projeto que se vinculou ao nacionalismo e à promessa de justiça social, centrada nos direitos do trabalho. Antes de 1945, utilizou-se dos direitos sociais, desvinculando-os dos políticos e, por isso, pouco contribuiu para o estabelecimento de uma sociedade democrática. No pós-1945, isso se alterou, havendo outra relação entre os direitos de cidadania que integrariam a idéia de justiça social, embora ela ainda permanecesse sendo afiançada pelo Estado.

Anos 90, Porto Alegre, v. 11, n. 19/20, p.11-20, jan./dez. 2004 
É evidente que, como ideologia e projeto políticos, o trabalhismo lançou raízes na experiência do movimento operário e sindical da Primeira República, no sentido thompsoniano. Logo, se essa ideologia foi inventada no pós-1930, não o foi de modo fortuito, arbitrário e a partir do nada. Seu poder de significação e mobilização (a "comunidade de sentidos" que logrou estabelecer) veio da releitura que as elites políticas do pós-1930 realizaram daquilo que ocorreu no terreno das lutas dos trabalhadores antes de 1930. Dizer isso não é admitir que houve trabalhismo ou trabalhistas no pré-1930. Por conseguinte, quando, em 1945, iniciou-se, ainda sob o Estado Novo, um movimento de organização de partidos políticos, os ideólogos do trabalhismo realizaram um certo esforço para criar um partido capaz de abrigar tal ideologia, que conviveria com eleições, voto etc. Contudo, é bom remarcar, isso não foi nada extremamente difícil, sobretudo com a bênção de Vargas e o suporte do aparelho sindical já razoavelmente estruturado. Foi assim que nasceu o Partido Trabalhista Brasileiro (PTB) ou o trabalhismo em seu primeiro tempo, constituindo-se numa desejada e clara alternativa aos apelos do Partido Comunista junto aos trabalhadores.

Esse tempo primordial foi o da República de 1945-64, quando, por meio dos sindicatos e do PTB, o trabalhismo seria relido e apropriado por trabalhadores e por lideranças políticas e sindicais, ganhando novos sentidos, forças e possibilidades. Foi então, a meu juízo e de outros analistas, que o trabalhismo transformou-se efetivamente em um instrumento de inclusão social e de alargamento da participação política, mesmo que se considere a existência de limites e constrangimentos a tal operação e também sua vinculação a práticas demagógicas e assistencialistas. Como escreve Renato Lessa,

[...] o trabalhismo enquanto fenômeno político e social só pode ser entendido se o associarmos à experiência da República de 1946 e a seus traços básicos: democracia política, legislação social progressiva, nacionalismo, presença marcante do Estado, modernização social e crescimento econômico (Lessa, 2004, p.12).

Anos 90, Porto Alegre, v. 11, n. 19/20, p.11-20, jan./dez. 2004 
Isso significa que o trabalhismo foi um dos principais legados da chamada Era Vargas, ainda que só possa ser bem entendido a partir das apropriações decorrentes do regime liberal-democrático estabelecido em 1946.

Desde 1946, portanto, o trabalhismo começou a ser compartilhado, em novas bases, em um circuito que comunica setores das elites com setores populares, ganhando sentidos específicos em cada um deles, o que se altera em cada conjuntura política. Assim, é possível dizer, correndo alguns riscos, que é justamente durante essa experiência que o trabalhismo começou a se constituir em uma tradição da política brasileira, capaz de mobilizar eleitores e de ser mobilizada por políticos. Sobretudo após a morte de Vargas, o primeiro e maior nome do trabalhismo, abriu-se uma temporada de disputas iniciadas pela redefinição dos conteúdos do trabalhismo, bem como uma luta, até antropofágica, pela herança do carisma de Vargas e pela força da legenda trabalhista. De 1954 a 1964, vários foram os partidos trabalhistas e várias as lideranças que, no interior do PTB, disputaram o poder de redefinir os conteúdos programáticos do partido e suas bases de atuação. Esse foi um segundo tempo do trabalhismo, de um trabalhismo sem Vargas, dominado pelas figuras de Jango, Fernando Ferrari, Lúcio Bittencourt, Leonel Brizola e San Tiago Dantas, entre outros. ${ }^{4}$

Nesse segundo tempo, a ideologia e a tradição trabalhistas continuaram marcadas pela defesa dos direitos do trabalhador, pelo nacionalismo e pela proposta de um Estado intervencionista e protetivo, mas vincularam-se a novos temas e interpelações, entre os quais o da luta pelas reformas de base. A tradição trabalhista transformava-se para sobreviver à perda de Vargas e para acompanhar o próprio crescimento do PTB, que se interiorizava, tornando-se um partido de âmbito nacional presente nas cidades e no interior.

Esse movimento do PTB e do trabalhismo para a "esquerda" teve episódios de grande disputa e radicalização, sendo interrompido pelo golpe civil e militar de 1964. E foi sobre o PTB e sobre as lideranças sindicais trabalhistas que a repressão mais rápida e duramente se abateu. Somente na década de 1980, após a anistia,

Anos 90, Porto Alegre, v. 11, n. 19/20, p.11-20, jan./dez. 2004 
em 1979, e com a volta de Leonel Brizola, anunciou-se um terceiro tempo da tradição trabalhista. Dessa feita, o trabalhismo encarnou-se no brizolismo, e a tradição, mais uma vez, transformou-se para se fortalecer e sobreviver. Nessa conjuntura, os temas da defesa dos direitos do trabalhador e do nacionalismo igualmente permaneceram patrimônio indiscutível que eram dessa tradição. Mas, ao lado deles, cresceram em importância tanto a questão da defesa da democracia, até porque minimizada em 1963-64, como a busca de uma definição para um socialismo brasileiro. Isso, de certa forma, pode ser entendido como uma nova tentativa de se realizarem as reformas de base, dessa feita na lei, e não mais na marra.

De 1942 a 2004, quando Brizola morreu, foram vários os trabalhismos que existiram e ainda existem no Brasil. O que é interessante enfatizar, para concluir, é que o trabalhismo pode ser considerado uma das tradições a integrar o que seria uma cultura política brasileira do pós-1945. Estou entendendo, portanto, como muitos historiadores e antropólogos, que uma cultura política é um conjunto de referências, mais ou menos formalizadas em instituições (no caso, partidos e sindicatos) e mais ou menos difundidas na sociedade. Ela não é homogênea e sofre transformações temporais e espaciais. É uma categoria polêmica, mas sua utilidade vem sendo testada em pesquisas que procuram entender de forma menos abstrata o comportamento e os valores políticos de atores individuais e coletivos. O trabalhismo é, nesse caso, uma boa oportunidade. Ainda que seja muito difícil saber se ele vai conseguir se transformar e renovar-se para sobreviver, não há dúvida de que o trabalhismo pode ser reconhecido como uma das ideologias e tradições mais importantes da cultura política do Brasil republicano.

\section{Brizola and labourism}

Abstract. According to reflections risen by Leonel Brizola's funeral, this article analyses labourism while political tradition and ideology, as part of a political culture shared in Brazil after 1945. This article shows how labourism, emerged after 1930's, was re-read and taken by workers, political and union leaders between 1945-1964. It shows also the changes occured after Vargas' suicide, as well as the changes labourism has suffered after 1979, when labourism became "brizolismo". Keywords: Brizolismo. Labourism. Political culture.

Anos 90, Porto Alegre, v. 11, n. 19/20, p.11-20, jan./dez. 2004 


\title{
Brizola e o trabalhismo
}

\begin{abstract}
Notas
${ }^{1}$ Nos últimos cinco anos, o professor Jorge Ferreira e eu insistimos muito para realizar uma entrevista de história de vida com Leonel Brizola. Telefonamos, escrevemos carta, conversamos. Ele concordava com a importância do depoimento, mas jamais aceitava marcar o início das gravações. Ficava evidente que, para ele, outras ações, mais urgentes, impunham-se, sendo a entrevista uma tarefa para o futuro. Infelizmente, esse futuro não chegou e, a despeito de se terem muitas entrevistas de Brizola, ele não deixou uma história de vida.

${ }^{2}$ Seria possível realizarem-se outras inclusões, verificando-se os funerais realizados nos estados, com as mesmas características de fundo. O funeral de João Pinheiro, em Minas Gerais, é um bom exemplo. Sobre esse episódio, ver Gomes (no prelo). ${ }^{3}$ Foram consultados apenas alguns jornais para a elaboração dessas reflexões, que se pretendem preliminares. Na cidade do Rio de Janeiro, o Jornal do Brasil, de 22 e 23 de junho de 2004, e $O$ Globo, de 23 de junho de 2004, que dedicou um caderno especial à morte de Brizola: O fim de uma era. Em Porto Alegre, consultouse Zero Hora, de 26 de junho de 2004.

${ }^{4}$ Sobre esse momento, ver Gomes (1994).
\end{abstract}

\section{Referêncas}

GOMES, Angela de Castro. Trabalhismo e democracia: o PTB sem Vargas. In:_ (Org.). Vargas e a crise dos anos 50. Rio de Janeiro: Relume Dumará, 1994. p. 133-160.

Memória, política e tradição familiar: os Pinheiro de Minas Gerais. In:_ (Org.). Minas e os fundamentos do Brasil moderno. Belo Horizonte: Ed. UFMG. No prelo.

GONÇALVES, João Felipe. Enterrando Rui Barbosa: um estudo de caso da construção fúnebre de heróis nacionais na Primeira República. Estudos Históricos, Rio de Janeiro, v. 14, n. 25, p. 135-162, 2000.

LESSA, Renato. Dois legados que mudaram o país. O Globo, p.12, 22 ago. 2004. Caderno Especial Getúlio Vargas.

Anos 90, Porto Alegre, v. 11, n. 19/20, p.11-20, jan./dez. 2004 